\title{
ANALISIS EFISIENSI TEKNIS KARET PERKEBUNAN RAKYAT KABUPATEN BANYUASIN PROVINSI SUMATERA SELATAN
}

\author{
Ario Pratama*1, Rahmat Syahni ${ }^{2}$, Mahdi $^{2}$ \\ ${ }^{1}$ Mahasiswa Magister Ilmu Ekonomi Pertanian Fakultas Pertanian Universitas Andalas \\ ${ }^{2}$ Staf Pengajar Program Studi Ilmu Ekonomi Pertanian Fakultas Pertanian Universitas Andalas \\ e-mail: *11820262007_ario@student.unand.ac.id
}

\begin{abstract}
The average productivity of rubber smallholder in Banyuasin Regency is 0,89 ton/ha lower than its potential productivity 1,5 ton/ha. This study aims to analyze the factors affecting rubber productivity, the level of technical efficiency and factors affecting technical inefficiency in rubber plantation at several group of plant age. The research used purposive sampling which obtained 60 samples of farmers as respondent and was conducted in Banyuasin Regency, South Sumatera Province from April to June 2020. Data were analyzed using stochastic frontier Cobb Douglas analysis. The results showed that factors affecting rubber productivity were TSP, Fungicide, Herbicide, labour, numbers of plant (tree), plant age and clone. The level of rubber smallholder technical efficiency showed the various amount from 0.50 to 0.97 with average level 0.87 . The highest average level of rubber smallholder technical efficiency was found at group of plant age 6-15 with TE 0.91. Factors affecting technical inefficiency were farmer's education, training and farmers status.
\end{abstract}

Keywords: Productivity, Technical efficiency, rubber, stochastic frontier

\section{PENDAHULUAN}

Karet dengan nama latin Hevea brasiliensis dikenal di Indonesia sejak masa kolonial Belanda dan merupakan salah satu komoditas penting perkebunan selain kelapa sawit, kopi dan kakao yang memberikan sumbangan besar bagi perekonomian negara. Indonesia pernah menguasai produksi karet dunia dan mengungguli hasil dari negara-negara lain dan negara asal tanaman karet sendiri yaitu di daratan Amerika Selatan. Posisi Indonesia sebagai produsen karet nomor satu di dunia akhirnya terdesak oleh dua negara, Malaysia dan Thailand (Tim Penulis Penebar Swadaya, 2013). Sebagai produsen karet nomor dua di dunia permasalahan produktivitas yang rendah masih harus ditingkatkan oleh Indonesia. Perkebunan-perkebunan karet banyak tersebar di berbagai provinsi di Indonesia salah satunya provinsi Sumatera Selatan. Produksi karet di Sumatera Selatan khususnya kabupaten Banyuasin selama tiga tahun terakhir sangat fluktuatif, penyebabnya karena masih belum optimalnya penggunaan input produksi juga teknologi budidaya. Tingkat produktivitas karet pada beberapa kabupaten sentra produksi di Provinsi Sumatera Selatan termasuk kabupaten Banyuasin yang masih rendah dengan rata-rata produktivitas sekitar 0,89 ton/ha (BPS Sumatera Selatan, 2020), masih sangat jauh dari produktivitas potensial yaitu 1,5 ton/ha diduga karena adanya ketidakefisienan dalam teknik budidaya serta masih banyak petani karet yang melakukan penyadapan pada usia tanaman karet yang sudah tidak produktif. Maka dari itu 
perlu adanya pengukuran tingkat efisiensi dalam upaya peningkatan produktivitas dilihat dari kelompok umur tanaman karet karena perluasan areal dan adopsi teknologi baru relatif sulit dilakukan dalam jangka pendek. Penelitian (Hutagaol, 2015) mengemukakan bahwa tanaman karet yang berumur 8-13 tahun memiliki efisiensi usahatani terbesar. Sejalan dengan penelitian (Damanik, 2012) yang menyatakan bahwa produksi puncak dicapai pada umur tahun sadap antara 8-9 tahun. Efisiensi teknis merupakan kemampuan petani untuk memperoleh output secara maksimal dari input yang ada, sedangkan efisiensi alokatif mengukur kemampuan dari suatu usahatani dalam menggunakan input-input secara proporsional pada tingkat harga dan teknologi produksi masing-masing (Coelli et. all 2005). Tingkat produksi karet yang rendah juga menjadi indikator usahatani karet belum efisien. Efisiensi teknis usahatani merupakan salah satu indikator dari kinerja usahatani. Menurut (Poungchompu, 2015) parameter inefisiensi pada petani karet salah satunya yaitu faktor sosial seperti umur, tingkat pendidikan, jumlah keluarga, gender, dan usia tanaman karet. Hal lainnya seperti manajerial petani dalam mengelola usahatani karet juga sangat penting, sehingga akan berpengaruh pada tingkat efisiensi usahatani karet. Sedangkan menurut hasil penelitian (Kuswanto, 2019) tentang dampak efisiensi produksi karet terhadap kesejahteraan petani karet di provinsi Jambi, terdapat empat faktor yang mempengaruhi produksi karet yaitu tenaga kerja, luas area lahan, usia tanaman dan pemupukan. Penggunaan tenaga kerja, luas area lahan dan usia tanaman merupakan faktor yang sangat berpengaruh yaitu sekitar 99\% sementara penggunaan pupuk urea berperan sekitar 90\% dalam produksi karet. Berdasarkan permasalahan diatas maka tujuan dari penelitian ini adalah untuk : 1) Menganalisis Faktorfaktor apa saja yang mempengaruhi produktivitas karet di Kabupaten Banyuasin Provinsi Sumatera Selatan. 2) Menganalisis tingkat efisiensi teknis serta faktor-faktor yang mempengaruhi inefisiensi teknis usahatani karet pada beberapa kelompok umur tanaman di Kabupaten Banyuasin Provinsi Sumatera Selatan.

\section{METODE PENELITIAN}

Metode yang digunakan dalam penelitian ini adalah metode pendekatan survei.Menurut Nazir (2005), metode survei adalah metode yang digunakan untuk menyelidiki, membedah dan mengevaluasi keadaan untuk memperoleh fakta dari gejala gejala yang ada dan mencari keterangan-keterangan secara faktual baik tentang institusi sosial, ekonomi, maupun politik dari suatu kelompok ataupun daerah.Penelitian ini dilakukan di wilayah Kabupaten Banyuasin Provinsi Sumatera Selatan. Penentuan lokasi penelitian dilakukan secara sengaja (purposive). Berdasarkan data yang ada bahwa hampir seluruh kecamatan di Kabupaten Banyuasin memproduksi karet maka dipilih kecamatan Sembawa dengan pertimbangan kecamatan ini merupakan sentra produksi dengan jumlah produksi tertinggi di Kabupaten Banyuasin. Selanjutnya setelah menentukan kecamatanditentukan tiga desa yaitu Desa Pulau Harapan, Desa Mainan dan Desa Santan Sari.

Penentuan sampel dilakukan dengan metode simple random sampling terhadap petani yang memenuhi kriteria yaitu petani yang memiliki lahan karet yang sudah menghasilkan dan bersedia untuk diwawancarai. Jumlah sampel yang diambil sebanyak 60 sampel petani dan terdistribusi secara merata pada ketiga desa tersebut. 
Pada penelitian ini, petani karet dibagi menjadi tiga kelompok berdasarkan umur tanaman yang dimiliki dengan acuan pada Manajemen dan Teknologi Budidaya Karet (Anwar, 2001). Pengelompokan tanaman karet menghasilkan/TM yaitu sebagai berikut :

1. Petani yang memiliki tanaman karet pada umur tanaman 6-15 tahun (18 orang)

2. Petani yang memiliki tanaman karet pada umur tanaman 16-25 tahun 23 (orang)

3. Petani yang memiliki tanaman karet pada umur tanaman $>25$ tahun (19 orang)

Berdasarkan sumbernya, data yang digunakan dalam penelitian ini adalah data primer dan data sekunder baik yang bersifat kualitatif maupun kuantitatif. Data primer diperoleh dengan cara pengamatan secara langsung di lokasi penelitian dan wawancara yang dilakukan secara terstruktur kepada petani rakyat yang dijadikan sebagai respondendengan menggunakan kuisioner yang meliputi karakteristik petaniresponden dan karakteristik usahatani. Sedangkan data sekunder adalah data yang dibutuhkan untuk melengkapi data primer guna memberi gambaran informasi secara detail.

Pada penelitian ini, variabel yang diamati adalah data dan informasi usahatani karet yang diusahakan oleh petani. Variabel tersebut anara lain sebagai berikut : Produktivitas karet (Y), Pupuk Urea $\left(\mathrm{X}_{1}\right)$, Pupuk TSP $\left(\mathrm{X}_{2}\right)$, Pupuk KCI $\left(\mathrm{X}_{3}\right)$, Fungisida $\left(\mathrm{X}_{4}\right)$, Herbisida cair $\left(\mathrm{X}_{5}\right)$, Tenaga kerja $\left(\mathrm{X}_{6}\right)$, Jumlah Pohon Karet $\left(\mathrm{X}_{7}\right)$, Umur tanaman $\left(\mathrm{X}_{8}\right)$, Klon $\left(\mathrm{X}_{9}\right)$, Umur petani $\left(Z_{1}\right)$, Pendidikan petani $\left(Z_{2}\right)$, Pengalaman berusahatani $\left(Z_{3}\right)$, Luas Lahan $\left(Z_{4}\right)$, Pelatihan $\left(Z_{5}\right)$ dan Status Usahatani $\left(Z_{6}\right)$.

\section{Metode Analisis Data}

Data primer dan sekunder yang diperoleh diolah dan dianalisis dengan metode kualitatif maupun kuantitatif. Analisis kualitatif diuraikan secara deskriptif untuk mengetahui gambaran umum lokasi penelitian, sedangkan metode kuantitatif dilakukan dengan menggunakan fungsi produksi stochastic frontier Cobb-Douglas untuk menganalisis efisiensi teknis usahatani karet di Kabupaten Banyuasin. Data kuantitatif yang diperoleh diolah menggunakan program Stata 14.2.

Fungsi produksi yang digunakan untuk menganalisis tujuan pertama adalah fungsi produksi stochastic frontier Cobb-Douglas berdasarkan model yang dikembangkan oleh Coelli et al. (2005). Tahap awal dari pembentukan model adalah melakukan penentuan variabel penelitian.Model persamaan penduga fungsi produksi frontier dari usahatani karet adalah sebagai berikut:

$$
\begin{aligned}
& \text { Ln } Y=\beta_{0}+\beta_{1} \ln X_{1}+\beta_{2} \ln X_{2}+\beta_{3} \ln X_{3}+\beta_{4} \ln X_{4}+\beta_{5} \ln X_{5}+\beta_{6} \ln X_{6}+\beta_{7} \ln X_{7} \\
& +\beta_{8} \ln D_{1}+\beta_{9} \ln D_{2}+\beta_{10} \ln D_{3}+v i-\text { ui }
\end{aligned}
$$

dimana:

$\mathrm{Y}=$ produktivitas karet $(\mathrm{kg} / \mathrm{ha} / \mathrm{thn})$

$\mathrm{X}_{1} \quad=$ jumlah Pupuk Urea $(\mathrm{Kg} / \mathrm{ha} / \mathrm{thn})$

$\mathrm{X}_{2} \quad=$ Jumlah Pupuk TSP $(\mathrm{Kg} / \mathrm{ha} / \mathrm{thn})$

$\mathrm{X}_{3}=$ Jumlah Pupuk KCI $(\mathrm{Kg} / \mathrm{ha} / \mathrm{thn})$

$\mathrm{X}_{4} \quad=$ Jumlah Fungisida (liter/ha/thn)

$\mathrm{X}_{5}=$ Jumlah Herbisida (liter/ha/thn) 
$\mathrm{X}_{6} \quad=$ Jumlah Tenaga Kerja $(\mathrm{HOK} / \mathrm{ha} / \mathrm{thn})$

$\mathrm{X}_{7}=$ Jumlah Pohon Karet

$\mathrm{X}_{8} \quad=\mathrm{D}_{1}:$ DummyUmur Tanaman, dimana :

$1=$ Tanaman berumur 16-25 tahun

$0=$ Tanaman berumur $<16$ tahun dan $>25$ tahun

D2: Dummy Umur Tanaman, dimana :

$1=$ Tanaman berumur $>25$ tahun

$0=$ Tanaman berumur $<25$ tahun

$\mathrm{X}_{9} \quad=\mathrm{D}_{3}$ : Dummy penggunaan Klon, $1=$ klon anjuran $0=$ selain klon anjuran

$\beta_{0} \quad=$ intersep

$\beta_{\mathrm{j}} \quad=$ koefisien parameter penduga, dimana $\mathrm{j}=1,2,3, \ldots, 7$

$0<\beta_{\mathrm{j}}<1$ (diminishing return)

ui $\quad=$ efek inefisiensi teknis dalam model

$\mathrm{Vi}=$ variabel acak

$\mathrm{Vi-} \mathrm{ui}_{\mathrm{i}}=$ error term total

Untuk tujuan penelitian kedua Analisis efisiensi teknis dapat diukur dengan menggunakan rumus sebagai berikut:

$$
\mathrm{TE}_{i}=\frac{y_{i}}{\exp \left(X_{i} \beta\right)}=\frac{\exp \left(x_{i} \beta-u_{i}\right.}{\exp \left(x_{i} \beta\right)}=\exp \left(-u_{i}\right)
$$

TEi adalah efisiensi teknis petani ke-i, yi adalah fungsi output deterministik (tanpa error term), dan exp (-ui) adalah nilai harapan (mean) dari ui. Nilai efisiensi teknis berkisar antara $0-1$, berbanding terbalik dengan nilai efek inefisiensi teknis dan hanya digunakan untuk fungsi yang memiliki jumlah ouput dan input tertentu (cross section data). Nilai efisiensi teknis petani dikatakan cukup efisien jika bernilai $\geq 0.7$ dan belum efisien jika bernilai < 0.7 (Kumbakar dan Lovell, 2000).

Model efek inefisiensi yang digunakan dalam penelitian ini berpedoman pada model efek inefisiensi teknis yang dikembangkan oleh Coelli et al. (2005). Variabel ui yang digunakan untuk mengukur efek inefisiensi teknis, diasumsikan bebas dan distribusinya terpotong normal dengan $N\left(\mu_{i}, \delta_{2}\right)$. Parameter distribusi $\left(\mu_{i}\right)$ efek inefisiensi teknis dalam penelitian ini dirumuskan sebagai berikut:

$$
\mu_{i}=\delta_{0}+\delta_{1} Z_{1}+\delta_{2} Z_{2}+\delta_{3} Z_{3}+\delta_{4} Z_{4}+\delta_{5} Z_{5}+\delta_{6} Z_{6}+w_{i t}
$$

Dimana faktor-faktor yang diduga mempengaruhi tingkat inefisiensi teknis petani karet adalah:

$\mu_{\mathrm{i}}=$ efek inefisiensi teknis

$\mathrm{Z}_{1}=$ umur petani (tahun)

$\mathrm{Z}_{2}=$ pendidikan petani (tahun)

$\mathrm{Z}_{3}=$ pengalaman usahatani karet (tahun)

$\mathrm{Z}_{4}=$ luas lahan (hektar)

$\mathrm{Z}_{5}=$ dummy pelatihan, $\quad 1=$ petani yang mendapatkan pelatihan

$0=$ petani yang tidak mendapatkan pelatihan

$\mathrm{Z}_{6}=$ dummy status usahatani, $1=$ pekerjaan utama

$0=$ pekerjaan sampingan

$\mathrm{Wit}_{\mathrm{it}}=$ error term

Nilai koefisien parameter yang diharapkan $\delta_{1}>0$ dan $\delta_{2}, \delta_{3}, \delta_{4}, \delta_{5}, \delta_{6}<0$. 


\section{HASIL DAN PEMBAHASAN}

\section{Analisis Fungsi Produksi Usahatani Karet}

Variabel yang diduga berpengaruh terhadap produktivitas karet (Variabel dependen/Y) digunakan sebagai variabel penjelas (variabel independen/X). Variabel tersebut terdiri dari : pupuk Urea, TSP, Kcl, Fungisida, Herbisida, Tenaga Kerja, Umur Tanaman dan Klon. Tabel lberikut menyajikan data deskriptif statistik variabel fungsi produksi stochastic frontier Cobb-Douglas pada usahatani karet perkebunan rakyat dapat dilihat bahwa rata-rata produktivitas karet perkebunan rakyat sebesar $1181.55 \mathrm{~kg} / \mathrm{ha}$. Pupuk Urea menjadi pupuk yang paling banyak digunakan oleh petani pada lokasi penelitian dibandingkan pupuk lainnya. Pupuk Urea yang digunakan oleh petani rata-rata sebesar $130.43 \mathrm{~kg} / \mathrm{ha}$. Pupuk TSP cenderung tidak terlalu banyak digunakan oleh petani dengan nilai rata-rata penggunaan sebesar 44.16 $\mathrm{kg} / \mathrm{ha}$. Sedangkan pupuk $\mathrm{KCl}$ rata-rata digunakan oleh petani sebesar $41.41 \mathrm{~kg} / \mathrm{ha}$. Penggunaan Fungisida cukup bervariasi dilihat dari standard deviasi yang lebih besar dari nilai rata-rata yaitu sebesar $7 \mathrm{~kg} / \mathrm{ha}$. Herbisida rata-rata digunakan petani sebesar $2.93 \mathrm{liter} / \mathrm{ha}$ dan jumlah pohon karet produktif rata-rata sebesar 520,73. Untuk beberapa faktor produksi (Pupuk Urea, TSP, KCl, Fungisida dan Herbisida) nilai minimumnya nol yang menunjukkan bahwa tidak semua petani menggunakan faktor produksi tersebut. Tenaga kerja yang merupakan salah satu faktor produksi terpenting, digunakan rata-rata sebesar 437.16 HOK.

Tabel 1. Deskriptif Statistik Variabel Fungsi Produksi Stochastic Frontier CobbDouglas Pada Usahatani Karet Perkebunan Rakyat di Kabupaten Banyuasin 2019

\begin{tabular}{lcccc}
\hline \multicolumn{1}{c}{ Variabel } & Rata-rata & $\begin{array}{c}\text { Standar } \\
\text { Deviasi }\end{array}$ & Minimum & Maksimum \\
& & 299.74 & 530 & 1827 \\
\hline Produktivitas (Y) & 1181.55 & 55.59 & 0 & 350 \\
Pupuk Urea (X1) & 130.43 & 46.22 & 0 & 150 \\
Pupuk TSP (X2) & 44.16 & 44.94 & 0 & 150 \\
Pupuk KC1 (X3) & 41.41 & 20.87 & 0 & 100 \\
Fungisida (X4) & 7 & 2.39 & 0 & 10 \\
Herbisida (X5) & 2.93 & 74.80 & 249 & 598 \\
Tenaga Kerja (X6) & 437.16 & 106.35 & 200 & 700 \\
Jumlah Pohon (X7) & 520.73 & & &
\end{tabular}

Sumber : data primer, 2019

\section{Pendugaan Fungsi Produksi Stochastic Frontier}

Model fungsi produksi ini dilakukan melalui dua tahap menggunakan metode penduga Maximum Likelihood Estimation (MLE). Tahap pertama menggunakan metode OLS (Ordinary Least Square) selanjutnya pada tahap kedua menggunakan metode MLE untuk menduga keseluruhan parameter faktor produksi, intersep, dan varians dari kedua komponen kesalahan vi dan ui serta untuk melihat tingkat efisiensi teknis dan apa saja faktor-faktor yang 
mempengaruhi inefisiensi teknis pada produksi karet di Kabupaten Banyuasin.Hasil estimasi model fungsi produksi Cobb-Douglas dengan metode OLS disajikan pada tabel 2.

Tabel 2. Pendugaan Fungsi Produkai Cobb-Douglas Dengan Metode OLS

\begin{tabular}{lccc}
\hline \multicolumn{1}{c}{ Variabel Input } & Koefisien & $\mathrm{t}$ & $\operatorname{Pr}>|\mathrm{t}|$ \\
\hline Konstanta & 3.831 & 3.87 & 0.000 \\
Pupuk Urea $\left(\mathrm{X}_{1}\right)$ & $0.090^{\mathrm{a}}$ & 2.72 & 0.009 \\
Pupuk TSP $\left(\mathrm{X}_{2}\right)$ & $0.036^{\mathrm{a}}$ & 2.84 & 0.007 \\
Pupuk KCl $\left(\mathrm{X}_{3}\right)$ & -0.001 & -0.15 & 0.881 \\
Fungisida $\left(\mathrm{X}_{4}\right)$ & $-0.035^{\mathrm{b}}$ & -1.93 & 0.059 \\
Herbisida $\left(\mathrm{X}_{5}\right)$ & $-0.058^{\mathrm{b}}$ & -1.72 & 0.091 \\
Tenaga Kerja $\left(\mathrm{X}_{6}\right)$ & $0.292^{\mathrm{a}}$ & 2.12 & 0.039 \\
Jumlah Pohon $\left(\mathrm{X}_{7}\right)$ & 0.143 & 1.45 & 0.154 \\
Dummy Umur Tanaman (D1) & $0.145^{\mathrm{a}}$ & 2.41 & 0.020 \\
Dummy Umur Tanaman (D2) & $-0.309^{\mathrm{a}}$ & -4.47 & 0.000 \\
Dummy Klon (D3) & $0.172^{\mathrm{a}}$ & 2.62 & 0.012 \\
\hline R-Square & 0.7126 & & \\
Adj R-Square & 0.6539 & & \\
\hline
\end{tabular}

a signifikan pada taraf $\alpha 0.05 ;{ }^{b}$ nyata pada taraf $\alpha 0.10$

Berdasarkan hasil dugaan fungsi produksi dengan metode OLS pada Tabel 2 diatas nilai Koefisien determinasi ( $R$-square) sebesar 0.7126. Apabila nilai $R$-square semakin mendekati satu atau 100 persen maka dapat dikatakan bahwa model makin layak digunakan karena dapat meramalkan kondisi ke depan secara akurat. Hal ini berarti bahwa sebesar $71.26 \%$ variabel penduga/independen (variabel pupuk urea, pupuk TSP, pupuk $\mathrm{KCl}$, fungisida, herbisida, tenaga kerja, jumlah pohon, dummy umur tanaman dan dummy klon) dapat menjelaskan variabel dependen dan $28.74 \%$ sisanya dijelaskan oleh faktor lain di luar model.

Hasil pendugaan model fungsi produksi karet menunjukkan bahwa variabel yang berpengaruh secara signifikan pada taraf $\alpha 5$ persen yaitu variabel Pupuk Urea $\left(\mathrm{X}_{1}\right)$, Pupuk TSP $\left(\mathrm{X}_{2}\right)$, Herbisida (X5), Tenaga Kerja (X6), Dummy Umur Tanaman (D1), Dummy Umur Tanaman (D2 dan Dummy Klon (D3) sedangkan variabel Fungisida ( $\left.\mathrm{X}_{4}\right)$ berpengaruh secara signifikan pada taraf $\alpha 10$ persen. Variabel yang tidak berpengaruh secara signifikan yaitu Pupuk $\mathrm{KCl}\left(\mathrm{X}_{3}\right)$ danJumlah Pohon $\left(\mathrm{X}_{7}\right)$.

Tahap selanjutnya pada tahap kedua yaitu pendugaan fungsi produksi Cobb Douglas dengan metode MLE (MaximumLikelihood Estimation). Metode Maximum Likelihood Estimator (MLE) mampu menggambarkan kinerja terbaik (best practice) dari petani responden pada lokasi penelitian. Hasil estimasi model fungsi produksi Cobb-Douglas dengan metode MLE disajikan pada tabel 3. 
Tabel 3. Pendugaan Fungsi Produkai Cobb-Douglas Dengan Metode MLE

\begin{tabular}{lccc}
\hline \multicolumn{1}{c}{ Variabel Input } & Koefisien & $\mathrm{z}$ & $\operatorname{Pr}>|\mathrm{t}|$ \\
\hline Konstanta & 3.599 & 5.01 & 0.000 \\
Pupuk Urea $\left(\mathrm{X}_{1}\right)$ & 0.073 & 1.57 & 0.115 \\
Pupuk TSP $\left(\mathrm{X}_{2}\right)$ & $0.020^{\mathrm{b}}$ & 1.73 & 0.083 \\
Pupuk KCl $\left(\mathrm{X}_{3}\right)$ & 0.009 & 0.90 & 0.366 \\
Fungisida $\left(\mathrm{X}_{4}\right)$ & $-0.036^{\mathrm{a}}$ & -2.72 & 0.006 \\
Herbisida $\left(\mathrm{X}_{5}\right)$ & $-0.073^{\mathrm{a}}$ & -2.59 & 0.010 \\
Tenaga Kerja (X6) & $0.327^{\mathrm{a}}$ & 3.33 & 0.001 \\
Jumlah Pohon (X7) & $0.185^{\mathrm{a}}$ & 2.51 & 0.012 \\
Dummy Umur Tanaman (D1) & $0.105^{\mathrm{a}}$ & 2.41 & 0.016 \\
Dummy Umur Tanaman (D2) & $-0.208^{\mathrm{a}}$ & -2.96 & 0.003 \\
Dummy Klon (D3) & $0.166^{\mathrm{a}}$ & 3.41 & 0.001 \\
\hline
\end{tabular}

${ }^{\mathrm{a}}$ signifikan pada taraf $\alpha 0.05$, $^{\mathrm{b}}$ nyata pada taraf $\alpha 0.10$

Dari hasil pendugaan model fungsi produksistochastic frontier dengan metode MLE diatas ditemukan bahwa terdapat variabel yang tidak signifikan pada taraf 0.05 dan 0.10 yaitu variabel Pupuk Urea $\left(\mathrm{X}_{1}\right)$ dan Pupuk $\mathrm{KCl}\left(\mathrm{X}_{3}\right)$ sehingga kedua variabel tersebut tidak dimasukan untuk analisis selanjutnya.

Tabel 4. Pendugaan fungsi produkai Cobb-Douglas dengan metode MLE

\begin{tabular}{lccc}
\hline \multicolumn{1}{c}{ Variabel Input } & Koefisien & $\mathrm{z}$ & $\operatorname{Pr}>|\mathrm{t}|$ \\
\hline Konstanta & 3.790 & 5.52 & 0.000 \\
Pupuk TSP $\left(\mathrm{X}_{2}\right)$ & $0.022^{\mathrm{a}}$ & 2.35 & 0.019 \\
Fungisida $\left(\mathrm{X}_{4}\right)$ & $-0.037^{\mathrm{a}}$ & -2.63 & 0.009 \\
Herbisida $\left(\mathrm{X}_{5}\right)$ & $-0.076^{\mathrm{a}}$ & -2.74 & 0.006 \\
Tenaga Kerja $\left(\mathrm{X}_{6}\right)$ & $0.346^{\mathrm{a}}$ & 3.40 & 0.001 \\
Jumlah Pohon (X) & $0.196^{\mathrm{a}}$ & 2.85 & 0.004 \\
Dummy Umur Tanaman (D1) & $0.082^{\mathrm{b}}$ & 1.91 & 0.057 \\
Dummy Umur Tanaman (D2) & $-0.218^{\mathrm{a}}$ & 3.50 & 0.001 \\
Dummy Klon (D3) & $0.175^{\mathrm{a}}$ & 3.41 & 0.000 \\
${ }^{\mathrm{a}}$ signifikan pada taraf $\alpha 0.05 ;{ }^{\mathrm{b}}$ nyata pada taraf $\alpha 0.10$ & &
\end{tabular}

Dari Tabel 4 diketahui bahwa hasil parameter dugaan fungsi produksi Cobb-Douglas dengan metode MLE yang dilihat dari nilai koefisiennya mempunyai tanda positif dan negatif. Variabel yang bertanda positif dapat memberi pengaruh positif terhadap produktivitas karet yaitu Pupuk TSP (X2), Tenaga Kerja (X6), Jumlah Pohon (X7), Dummy Umur Tanaman (D1) dan Dummy Klon (D3) yang berpengaruh nyata pada taraf $\alpha=0.05$ dan 0.10 persen, sedangkan variabel yang bertanda negatif yaitu Fungisida (X4), Herbisida (Xs), Dummy Umur Tanaman (D2) memberi pengaruh negatif terhadap produktivitas karet di Kabupaten Banyuasin.

Pada fungsi produksi Cobb-Douglas nilai koefisien juga merupakan nilai elastisitasnya. Adapun nilai koefisien atau elastisitas produksi untuk variabel Pupuk TSP, Fungisida, Herbisida, Tenaga Kerja, Jumlah Pohon, Dummy Umur Tanaman, Dummy Umur 
Tanaman (D1), Dummy Umur Tanaman (D2) dan Dummy Klon masing-masing sebesar $0.022,-0.037,-0.076,0.346,0.196,0.082,-0.218$ dan 0.175 .

Variabel pupuk TSP memiliki nilai koefisien atau elastisitas sebesar 0.022 dan berpengaruh positif secara signifikan pada taraf $\alpha=0.05$ yang mengindikasikan bahwa setiap penambahan penggunaan pupuk TSP sebesar 1 persen maka produktivitas karet naik sebesar 0.022 persen. Nilai penambahan produktivitas karet dengan meningkatkan penggunaan pupuk TSP tiap 1 persennya tidak terlalu besar dikarenakan pada lokasi penelitian memang tidak semua petani responden menggunakan pupuk TSP juga penggunaannya tidak dilakukan secara teratur menurut pedoman budidaya yang ada.

Koefisien variabel fungisida berpengaruh negatif dan signifikan terhadap produktivitaskaret pada taraf nyata $\alpha=0.05$ dengan nilai koefisien sebesar -0.037 . Angka ini menunjukkan bahwa penambahan jumlah penggunaan fungisida sebesar 1 persen dengan input lainnya tetap, dapat menyebabkan menurunnya produktivitas karet di daerah penelitian sebesar -0.037 persen. Hal ini diduga terjadi karena penggunaan fungisida belum sepenuhnya dilakukan petani secara teratur karena menurut hasil wawancara di lokasi penelitian, serangan hama dan penyakit tidak terlalu berdampak terhadap produksi karet yaitu hanya sekitar $25 \%$. Variabel herbisida juga berpengaruh negatif terhadap produktivitas karet pada taraf nyata $\alpha=$ 0.05dan nilai koefisien sebesar -0.076 yang menunjukkan bahwa setiap penambahan herbisida sebesar 1 persen dan input lainnya tetap maka akan menurunkan produktivitas karet sebesar 0.076 persen. Kondisi ini dikarenakan petani lebih memilih memangkas gulma secara manual menggunakan parang daripada menggunakan herbisida yang dapat menambah pengeluaran biaya produksi dari usahatani karet.

Variabel tenaga kerja berpengaruh nyata pada taraf $\alpha=0.05$ dan memiliki nilai koefisien atau elastisitas yang paling besar yaitu 0.346 yang mengindikasikan bahwa variabel ini memiliki kontribusi yang dominan pada peningkatan produktivitas usahatani karet.Penambahan tenaga kerja sebesar 1 persen pada usahatani karet dapat meningkatkan produktivitas karet sebesar 0.346 persen. Penggunaan tenaga kerja di lokasi penelitian lebih banyak dilakukan oleh tenaga kerja luar keluarga pada kegiatan penyadapan, sedangkan untuk kegiatan pemupukan menggunakan tenaga kerja dalam keluarga dikarenakan intensitas pemupukan yang tidak dilakukan setiap hari. Hasil ini juga sejalan dengan penelitian Kuswanto (2019) dan Aliyu et al. (2017) yang menemukan bahwa jumlah tenaga kerja yang digunakan berpengaruh nyata secara positif terhadap produksi karet dan penambahan input berupa tenaga kerja dengan input lainnya tetap masih memungkinkan untuk meningkatkan produksi karet.

Elastisitas produksi batas dari variabel jumlah pohon berpengaruh positif dan signifikan terhadap produktivitas karet dengan nilai 0.196 pada taraf nyata $\alpha=0.05$. Hal ini menunjukkan bahwa dengan penambahan jumlah pohon karet menghasilkan sebesar 1 persen dengan input lain tetap akan meningkatkan produktivitas karet sebesar 0.196. Jumlah pohon karet menghasilkan pada lokasi penelitian rata-rata sebanyak 520.73 pohon. Banyaknya jumlah pohon karet menghasilan didasarkan pada luas lahan yang dimiliki oleh petani karet dan sistem jarak tanam yang diterapkan oleh petani.

Variabel dummy umur tanaman (D1) berpengaruh positif dan signifikan pada taraf $\alpha=$ 0.10 berbeda dengan variabel dummy umur tanaman (D2) yang berpengaruh negatif dan signifikan pada taraf $\alpha=0.05$. Hal tersebut menunjukkan bahwa terdapat keragaman 
produktivitas yang nyata antara kelompok tanaman berumur kurang dari 16 tahun dan 16-25 tahun yaitu dengan peningkatan tanaman karet pada kelompok umur tersebut sebesar 1 persen akan meningkatkan produktivitas karet sebesar 0.082 persen. Sejalan dengan penelitian Giroh and Adebayo (2007) yang menjelaskan bahwa umur tanaman karet yang lebih muda dapat meningkatkan produksi karet karena lebih menghasilkan daripada tanaman karet yang sudah tua. Berbeda dengan kelompok umur tanaman kurang dari 16 tahun dan 16-25 tahun, yang menjelaskan bahwa dengan peningkatan 1 persen tanaman pada kelompok umur tanaman $>25$ tahun akan menurunkan produktivitas karet sebesar - 0.218 persen. Variabel dummy klon (D3) memiliki nilai koefisien atau elastisitas sebesar 0.175 dan berpengaruh positif secara signifikan pada taraf $\alpha=0.05$. Artinya bahwa setiap penggunaan klon anjuran dapat meningkatkan produktivitas karet sebesar 0.175 persen.

\section{Analisis Efisiensi Teknis Usahatani Karet}

Tingkat efisiensi teknis pada penelitian ini diukur menggunakan model fungsi produksi cobb douglass dengan pendekatan stochastic frontier. Nilai efisiensi teknis petani dikatakan cukup efisien jika bernilai $\geq 0.7$ dan belum efisien jika bernilai $<0.7$ (Kumbakar dan Lovell, 2000). Hasil dari analisis berupa tingkat efisiensi dari setiap responden dikelompokkan berdasarkan kelompok umur tanaman dan disajikan pada Tabel 5 berikut.

Tabel 5. Tingkat Efisiensi Teknis Usahatani Karet di Kabupaten Banyuasin

\begin{tabular}{ccccc}
\hline \multirow{2}{*}{$\begin{array}{c}\text { Efisiensi } \\
\text { Teknis }\end{array}$} & $\begin{array}{c}\text { Umur Tanaman } \\
6-15 \text { tahun }\end{array}$ & $\begin{array}{c}\text { Umur Tanaman } \\
16-25 \text { tahun }\end{array}$ & $\begin{array}{c}\text { Umur Tanaman } \\
>25 \text { tahun }\end{array}$ & $\begin{array}{c}\text { Total } \\
\text { Keseluruhan }\end{array}$ \\
\cline { 2 - 5 } & 0 & 0 & 2 & 2 \\
$0,5-0,6$ & 0 & 0 & 5 & 5 \\
$0,6-0,7$ & 0 & 1 & 2 & 3 \\
$0,7-0,8$ & 4 & 10 & 4 & 18 \\
$0,8-0,9$ & 14 & 12 & 6 & 32 \\
$>0,9$ & 18 & 23 & 19 & 60 \\
\hline Jumlah & 0,91 & 0,90 & 0,79 & 0,87 \\
\hline Rata-rata TE & 0,81 & 0,79 & 0,50 & 0,50 \\
Minimum TE & 0,96 & 0,97 & 0,97 & 0,97 \\
Maksimum TE & & & & \\
\hline
\end{tabular}

Berdasarkan hasil analisis pada Tabel 5, nilai rata-rata efisiensi teknis petani karet pada lokasi penelitian secara keseluruhan sebesar 0,87 atau 87 persen dari produktivitas maksimum. Nilai rata-rata tersebut menunjukkan bahwa petani responden sudah cukup efisien tetapi petani masih memiliki peluang untuk mencapai produktivitas maksimum sebesar 13 persen. Sedangkan jika dilihat berdasarkan kelompok umur tanaman maka rata-rata tertinggi tingkat efisiensi teknis terdapat pada petani karet dengan kelompok umur tanaman 6-15 tahun yaitu sebesar 0,91 kemudian kelompok umur tanaman 16-25 tahun sebesar 0,90 dan efisiensi teknis paling rendah terdapat pada petani dengan kelompok umur tanaman $>25$ tahun.

\section{Faktor-Faktor yang Mempengaruhi Inefisiensi Teknis Petani Karet}

Terdapat enam variabel yang diduga menjadi faktor yang mempengaruhi inefisiensi teknis karet yaitu usia petani (X1), pendidikan formal (X2), pengalaman usahatani (X3), luas 
lahan (X4), dummy pelatihan (X5), dummy status usahatani (X6). Pendugaan efek inefisiensi teknis usahatani karet di Kabupaten Banyuasin disajikan pada Tabel 6.

Tabel 6. Pendugaan faktor yang mempengaruhi inefisiensi teknis fungsi produksi stochastic frontier usahatani karet di Kabupaten Banyuasin

\begin{tabular}{lccc}
\hline \multicolumn{1}{c}{ Variabel Input } & Koefisien & $\mathrm{z}$ & $\operatorname{Pr}>|\mathrm{t}|$ \\
\hline Konstanta & 0.428 & 0.22 & 0.828 \\
Usia Petani $\left(\mathrm{Z}_{1}\right)$ & 0.023 & 0.62 & 0.537 \\
Pendidikan Petani $\left(\mathrm{Z}_{2}\right)$ & -0.247 & -2.08 & 0.037 \\
Pengalaman usahatani $\left(\mathrm{Z}_{3}\right)$ & -0.026 & -0.70 & 0.486 \\
Luas Lahan $\left(\mathrm{Z}_{4}\right)$ & 0.483 & 1.02 & 0.306 \\
Pelatihan $\left(\mathrm{Z}_{5}\right)$ & -1.690 & -1.78 & 0.075 \\
Status Usahatani $\left(\mathrm{Z}_{6}\right)$ & -2.800 & -2.38 & 0.017 \\
\hline
\end{tabular}

${ }^{a}$ signifikan pada taraf $\alpha 0.05 ;$, nyata pada taraf $\alpha 0.10$

Koefisien usia petani responden bertanda positif namun tidak berpengaruh secara signifikan terhadap efek inefisiensi teknis. Hal ini menjelaskan bahwa efisiensi teknis dapat dicapai oleh petani karet yang berusia muda. Sejalan dengan kondisi di lokasi penelitian bahwa beban pekerjaan petani karet yang cukup berat terutama pada kegiatan penyadapan yang harus dimulai pada dini hari sangat membutuhkan kekuatan fisik yang prima.

Koefisien pendidikan petani memiliki nilai negatif dan signifikan pada taraf nyata 5 persen yang menunjukkan bahwa semakin tinggi pendidikan petani maka dapat mengurangi inefisiensi teknis usahatani karet. Semakin tinggi tingkat pendidikan yang dimiliki petani maka petani akan lebih mudah dalam menerima atau mengadopsi perubahan teknologi budidaya dan memilih input yang tepat untuk digunakan dalam usahatani sehingga berpengaruh pada manajemen usahatani dan mampu menurunkan inefisiensi dalam berusahatani. Hasil ini sejalan dengan penelitian Aliyu et al. (2017), bahwa faktor pendidikan petani berpengaruh negatif terhadap inefisiensi namun hal berbeda ditemukan oleh Anggraini (2015) pada penelitiannya yang menemukan bahwa peningkatan pendidikan petani dapat menurunkan efisiensi teknis atau berpengaruh positif terhadap inefisiensi teknis.

Koefisien pengalaman usahatani pada penelitian ini bertanda negatif terhadap inefisiensi dan tidak berpengaruh secara signifikan. Pengalaman usahatani pada lokasi penelitian cukup beragam dan rata-rata tertinggi terdapat pada kelompok pengalaman usahatani 17-28 tahun sebanyak 40 persen yang mengindikasikan bahwa petani responden di lokasi penelitian cukup berpengalaman.

Variabel luas lahan yang dimiliki petani responden memiliki koefisien bertanda positif dan tidak berpengaruh secara signifikan terhadap inefisiensi. Sebanyak 85 persen petani karet responden pada lokasi penelitian memiliki luas lahan dengan kategori sedang yaitu sekitar 1-2 hektar. Pada penelitian ini, faktor keikutsertaan petani dalam pelatihan budidaya karet bertanda negatif dan signifikan pada taraf nyata 5 persen yang menggambarkan bahwa petani yang pernah mengikuti pelatihan terkait budidaya karet dapat meningkatkan efisiensi teknis usahatani karet. Hal ini dikarenakan petani yang mengikuti pelatihan akan lebih memahami bagaimana proses usahatani karet yang baik mulai dari persiapan lahan, perawatan, pemanenan dan pengelolaan pascapanen. Namun fakta di lapangan ditemukan bahwa masih 
sangat sedikit petani yang mengikuti pelatihan budidaya karet hanya sekitar 33 persen petani responden disebabkan pelatihan dari pihak terkait belum dilakukan secara rutin dan merata kepada semua petani karet.

Dari hasil pendugaan terhadap efek inefisiensi menunjukkan bahwa status usahatani sebagai mata pencaharian bertanda negatif dan berpengaruh secara signifikan pada taraf nyata 5 persen. Pada lokasi penelitian ditemukan bahwa 93 persen status usahatani karet menjadikan usahatani karet sebagai mata pencarian/pekerjaan utama. Hal ini menjelaskan bahwa petani dengan mata pencaharian utama sebagai petani karet dapat menurunkan inefisiensi teknis yang berarti petani karet yang menjadikan usahatani karet sebagai pekerjaan utama lebih efisien secara teknis daripada petani karet yang menjadikan usahatani karet sebagai pekerjaan sampingan.

\section{KESIMPULAN DAN SARAN}

\section{Kesimpulan}

Berdasarkan tujuan penelitian dan hasil pembahasan maka dapat ditarik kesimpulan sebagai berikut

1. Faktor-faktor yang mempengaruhi produktivitas karet perkebunan rakyat di Kabupaten Banyuasin secara signifikanadalah pupuk TSP, Fungisida, Herbisida, tenaga kerja, jumlah pohon, umur tanaman dan klon.Faktor pupuk TSP, tenaga kerja, jumlah pohon, umur tanaman <16 tahun dan 16-25 tahun, dan klonberdampak positif terhadap produktivitas karet, sedangkan faktor Fungisida, Herbisidadan umur tanaman $>25$ tahun berdampak negatif pada produktivitas karet.

2. Tingkat efisiensi teknis usahatani karet perkebunan rakyat di Kabupaten Banyuasin secara keseluruhan cukup beragam mulai dari 0.50hingga 0.97 dengan rata-rata tingkat efisiensi teknis sebesar 0.87. Namun jika dilihat dari beberapa kelompok umur tanaman maka rata-rata tertinggi tingkat efisiensi teknis terdapat pada petani karet dengan kelompok umur tanaman 6-15 tahun yaitu sebesar 0.91 kemudian kelompok umur tanaman 16-25 tahun sebesar 0.90 dan efisiensi teknis paling rendah terdapat pada petani dengan kelompok umur tanaman $>25$ tahun sebesar 0.79 artinya petani sudah efisien secara teknis.

3. Faktor yang mempengaruhi efisiensi teknis secara signifikan adalah pendidikan, pelatihan dan status usahatani. Petani yang memiliki tingkat pendidikan tinggi akan mencapai tingkat efisiensi teknis yang lebih tinggi. Petani yang mengikuti pelatihan budidaya karet akan semakin efisien secara teknis. Petani yang menjadikan usahatani karet sebagai mata pencarian/pekerjaan utama lebih efisien dibanding petani karet dengan status pekerjaan sampingan.

\section{Saran}

Berdasarkan kesimpulan pada penelitian ini maka saran yang dapat diberikan adalah sebagai berikut:

1. Untuk meningkatkan produktivitas karet petani seharusnya memaksimalkan penggunaan input produksi seperti pupuk TSP, Fungisida, Herbisida, tenaga kerja, jumlah pohon, 
umur tanaman dan menggunakannyasecara tepatsesuai dosis serta dilakukan secara berkala.

2. Petani responden pada kelompok umur tanaman $>25$ tahun diharapkandapat melakukan peremajaan terhadap tanaman karet dikarenakan penambahan input produksi pada kelompok umur tanaman tersebut tidak terlalu berpengaruh lagi terhadap produktivitas sehingga hasil produksi karet yang didapatkan tidak optimal.

\section{DAFTAR PUSTAKA}

Aliyu A, Latifi IA, Shamsudin MN, Nawi NM. 2017. Factors Affecting Technical Efficiency of Rubber Smallholders in Negeri Sembilan, Malaysia. Journal of Agricultural Science; Vol. 9, No. 5 : 226-232.

Anggraini, Nuni. 2015. Efisiensi Pada Usahatani Ubikayu di Kabupaten Lampung Tengah Provinsi Lampung. [tesis]. Bogor (ID): Institut Pertanian Bogor.

Anwar, Chairil. 2006. Manajemen dan Teknologi Budidaya Karet. Pusat Penelitian Karet. Medan.

Badan Pusat Statistik. 2018. Provinsi Sumatera Selatan Dalam Angka 2018. Palembang. Badan Pusat Statistik Provinsi Sumatera Selatan

Coelli TJ, Rao DSP, O’Donnel CJ, Battese GE. 2005. An Introduction to Efficiency and Productivity Analysis. Second Edition. New York: SpringerScience and Business Media, Inc.

Damanik S. 2012. Pengembangan Karet (Havea brasiliensis) Berkelanjutan di Indonesia. Perspektif Vol. 11 No. 1 /Juni 2012. Hlm 91 - 102.

Giroh, D. Y., \& Adebayo, E. F. 2007. Analyzing the Technical efficiency of Rubber tapping in Nigeria. Journal of Agriculture and Social Sciences (Pakistan).

Hutagaol SN. 2015. Analisis Usahatani Karet (Hevea Brasiliensis) di Provinsi Jambi. [tesis].Bogor (ID): Institut Pertanian Bogor.

Kuswanto., Zulkifli Alamsyah., Armandelis., dan Zulfanetty. 2019. The Impact of the Efficiency of Rubber Production on the Welfare of Rubber Farmers in Jambi Province. International Journal of Economics and Financial Issues, 2019, 9(2), 80-86.

Nazir. 2005. Metoda Penelitian. Bogor : Ghalia Indonesia

Poungchompu, S., Chantanop, S. (2015), Factor affecting technical efficiency of smallholder rubber farming in Northeast Thailand. American Journal of Agricultural andBiological Sciences, 10(2), 83-90.

Subal C. Kumbhakar, C.A. Knox Lovell. 2000. Stochastic Frontier Analysis.2002. United Kingdom. Cambridge University Press.

Tim Penebar Swadaya. 2013. Panduan Karet Lengkap. Jakarta (ID): Penebar Swadaya. 